\title{
Human Neocortical Excitability Is Decreased during Anoxia Via Sodium Channel Modulation
}

\author{
Theodore R. Cummins, ${ }^{*}$ Chun Jiang, ${ }^{\star}$ and Gabriel G. Haddad * \\ *Interdepartmental Neuroscience Program, and ${ }^{\ddagger}$ Laboratory of Respiratory Neurobiology, Section of Respiratory Medicine, \\ Department of Pediatrics, Yale University School of Medicine, New Haven, Connecticut 06510
}

\begin{abstract}
When the central nervous system in humans is deprived of oxygen, the effects are potentially disastrous. Electroencephalographic activity is lost and higher brain function ceases rapidly. Despite the importance of these effects, the mechanisms underlying the loss of cortical activity are poorly understood. Using intracellular recordings of human neocortical neurons in tissue slices, we show that, whereas anoxia produces a relatively small depolarization and modest alterations in passive properties, it causes a major decrease in excitability. Whole-cell voltage-clamp studies of acutely isolated human neocortical pyramidal neurons demonstrate that anoxia and metabolic inhibition produce a large negative shift in the steady-state inactivation $[h \infty(V)]$ curve for the voltage-dependent sodium current $\left(I_{\mathrm{Na}}\right)$. Inclusion of ATP in the patch pipette decreased the shift of the $h \infty(V)$ curve by two-thirds. Because increased inactivation of $I_{\mathrm{Na}}$ decreases cellular metabolic demand, we postulate that this promotes neuronal survival during periods of oxygen deprivation. These data show a novel mechanism by which anoxia links metabolism to membrane ionic conductances in human cortical neurons. (J. Clin. Invest. 1993. 91:608-615.) Key words: ischemia $\bullet$ metabolic inhibition • neurons • oxygen deprivation
\end{abstract}

\section{Introduction}

The effect of oxygen deprivation on the central nervous system (CNS) in humans can be rapid and clinically catastrophic. Consciousness and higher brain functions are lost and electroencephalographic activity disappears quickly (1); prolonged periods of deprivation can lead to irreversible brain damage (2). Recent studies using in vitro preparations of animal tissues have investigated the cellular mechanisms underlying the neuronal response to anoxia (3-10). Although the results of these animal studies have been useful, it is still unclear how oxygen deprivation depresses brain electrical activity within brief time periods and how this depression relates to CNS injury. Because the majority of animal studies have focused on hippocampal (3-7) and brainstem $(8,9)$ tissue, little is known about how anoxia influences ionic conductances and cellular properties in animal neocortical neurons. This is particularly significant be-

Address reprint requests to Dr. G. G. Haddad, Section of Respiratory Medicine, Department of Pediatrics, Yale University School of Medicine, Fitkin Bldg. 5-506, 333 Cedar Street, New Haven, CT 06510.

Received for publication 19 February 1992 and in revised form 10 August 1992.

J. Clin. Invest.

(C) The American Society for Clinical Investigation, Inc.

0021-9738/93/02/0608/08 \$2.00

Volume 91, February 1993, 608-615 cause we now know that the sensitivity of the CNS to anoxia varies widely from one region to another (11). Furthermore, it is not known to what extent data pertaining to the neuronal response to anoxia in animal models (in vivo or in vitro) apply to human neurons. We have therefore taken advantage of a rare opportunity to study the anoxic response of human neocortical neurons in the human brain slice and dissociated human neocortical neurons.

\section{Methods}

Preparation of human brain slices. The methods for preparation of the human neocortical slices were similar to those previously described (12). These studies have been approved by our Institutional Human Investigation Committee and patient consent for the use of resected tissue was obtained. Briefly, a small portion of human neocortical tissue was obtained from 15 patients with temporal lobe epilepsy undergoing resection of the hippocampus, parahippocampus, and lateral amygdala. The anterolateral temporal tissue obtained for these studies was removed solely to gain access to the hippocampus and was judged to have normal excitability from intracranial chronic depth and subdural electrode recordings and/or intraoperative cortical surface electrocorticography which examined interictal electrical activity. In a separate study neocortical slices removed from these sites using the same selective criteria were demonstrated to be electrophysiologically and histologically normal (12). Neocortical tissue was resected by neurosurgeons (Drs. Dennis D. Spencer and Itzhak Fried) and a portion $\left(\sim 0.5-1.0 \mathrm{~cm}^{3}\right)$ of the excised tissue was placed in ice-cold Ringer's $\left(3-5^{\circ} \mathrm{C}\right)$. The tissue was rapidly transferred to the laboratory, sectioned into $400-\mu \mathrm{m}$ slices, and then placed in a slice recording chamber. The time from tissue resection to the placement of slices in the chamber was $10 \mathrm{~min}$ or less. These slices were continuously superfused with a medium containing (in $\mathrm{mM}$ ) $124.0 \mathrm{NaCl}, 2.5 \mathrm{KCl}, 1.25$ $\mathrm{NaH}_{2} \mathrm{PO}_{4}, 2.0 \mathrm{MgSO}_{4}, 2.0 \mathrm{CaCl}_{2}, 26.0 \mathrm{NaHCO}_{3}$, and 10.0 D-glucose that was oxygenated with $95 \% \mathrm{O}_{2}-5 \% \mathrm{CO}_{2}(\mathrm{pH} 7.4)$ and perfused with a flow of 1-2 $\mathrm{ml} / \mathrm{min}$. Warmed and humidified $95 \% \mathrm{O}_{2}-5 \% \mathrm{CO}_{2}$ also flowed over the surface of the slices. The temperature in the chamber was maintained at $35-36^{\circ} \mathrm{C}$. Anoxia (up to $40 \mathrm{~min}$ ) was induced by switching to the perfusate equilibrated with $95 \% \mathrm{~N}_{2}-5 \% \mathrm{CO}_{2}$, and by superfusing this same gas over the slices. In our slice system, $\mathrm{PO}_{2}$ started to decrease within $5 \mathrm{~s}$ after switching to $\mathrm{N}_{2}$ and became close to zero within 20-30 s (13).

Electrophysiologic measurements in human brain slices. Membrane potential $(\mathrm{Vm})^{1}$ was recorded using glass microelectrodes filled with $3 \mathrm{M} \mathrm{KCl}$ or $2 \mathrm{M}$ potassium acetate (resistance 60-100 $\mathrm{M} \Omega$ ). Membrane input resistance $(\mathrm{Rn})$ was measured by passing step hyperpolarizing currents through the recording electrode and recording voltage changes. Rheobase was taken as the minimal current that produces action potentials. To compare rheobase changes during anoxia, current was passed when there were no detectable changes in $\mathrm{Vm}$ and $\mathrm{Rn}$. Cells were accepted for further analyses only if $(a) \mathrm{Vm}$ was more negative than $-65 \mathrm{mV}$ and $(b)$ the amplitude of action potentials was $>80 \mathrm{mV}$.

1. Abbreviations used in this paper: $\mathrm{CN}$, sodium cyanide; EPSP, excitatory postsynaptic potential; $h \infty(V)$, steady-state inactivation curve; $\mathrm{I}_{\mathrm{Na}}$, sodium current; $\mathrm{Rn}$, membrane input resistance; $\mathrm{Vm}$, membrane potential. 


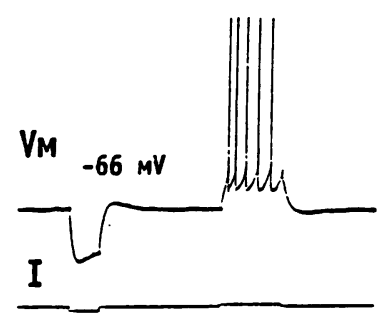

-0.2 NA

$+0.1 \mathrm{NA}$
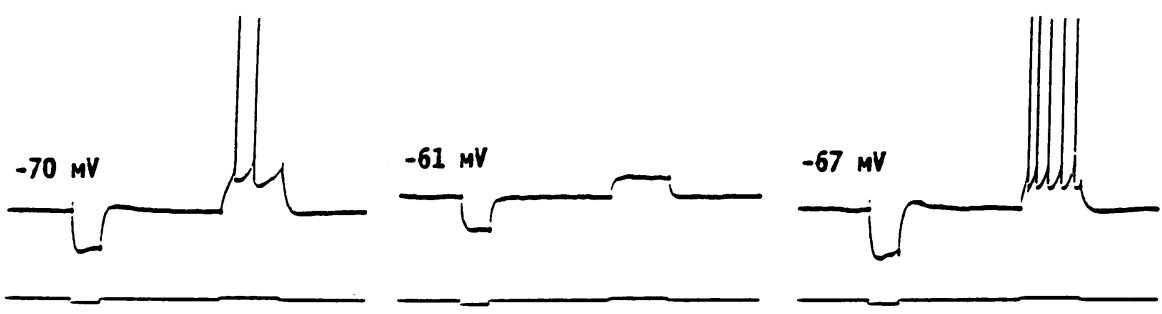

$400 \mathrm{~ms}$

Figure 1. Electrophysiologic responses of human neocortical neurons to anoxia. Intracellular recordings of a temporal cortical neuron were carried out in brain slices as previously described (12). Four short epochs extracted from continuous intracellular recordings, monitoring Vm, $\mathrm{Rn}$, and neuronal activity during baseline, anoxia ( 3 and $8 \mathrm{~min}$ ), and recovery. Note that $(a)$ excitability was reduced during anoxia as action potentials ceased for the same current injection; $(b) \mathrm{Rn}$ decreased during anoxia; and $(c)$ the human neocortical neuron hyperpolarized before it depolarized during the course of anoxia. After $\mathrm{O}_{2}$ was reinstituted, $\mathrm{Vm}, \mathrm{Rn}$, and rheobase returned to the baseline level.

Double-barreled (Capillaries, No. PB150F; World Precision Instruments, Sarasota, FL) microelectrodes similar to those described previously $(9,10)$ were employed for measurements of extracellular potassium activity $\left(\mathrm{K}_{0}^{+}\right)$. In brief, the ion-selective barrel was exposed to hexamethyldisilazan (Fluka Chemie AG, Ronkonkoma, NY) vapor for $1 \mathrm{~h}$ and then baked at $120^{\circ} \mathrm{C}$ for $2-3 \mathrm{~h}$. The tip of the ion-selective barrel was filled with valinomycin-based $\mathrm{K}^{+}$ionophore (Fluka, 60398 Potassium Ionophore 1-Cocktail B) and the remainder of the barrel backfilled with $0.1 \mathrm{M} \mathrm{KCl}$. This ionophore has a much greater measured selectivity for $\mathrm{K}^{+}$than various ions, e.g., $\mathrm{K}^{+} / \mathrm{Na}^{+}(1,000: 1)$. The other barrel was filled with $3 \mathrm{M} \mathrm{NaCl}$. Electrodes were used only if they showed an excellent sensitivity to $\mathrm{K}^{+}$(a voltage change $>70 \mathrm{mV}$ when $\mathrm{K}^{+}$concentration increased from 5 to $100 \mathrm{mM}$ ) and a high frequency response (time constant $<10 \mathrm{~s}$ after change of $\mathrm{K}^{+}$concentrations). The voltage recorded from the $\mathrm{NaCl}$ barrel was subtracted from that of the ion-selective barrel with a differential amplifier (with respect to a reference electrode filled with $3 \mathrm{M} \mathrm{KCl}$ ). Their difference (representing $\mathrm{K}^{+}$potential) was amplified, filtered $(0-100 \mathrm{~Hz})$ and displayed on a chart recorder. Serial calibrations of ion-selective microelectrodes were made with solutions containing $3.1,5,10,50$, and $100 \mathrm{mM} \mathrm{KCl}$. The osmolarity was balanced with $\mathrm{NaCl}$. $\mathrm{K}_{0}^{+}$was calculated by comparing voltage changes recorded from neurons with those obtained from calibration solutions.

Whole-cell patch-clamp recordings of human cortical neurons. Neurons were acutely isolated to study membrane currents using the whole-cell patch-clamp technique (14). The cell isolation procedure

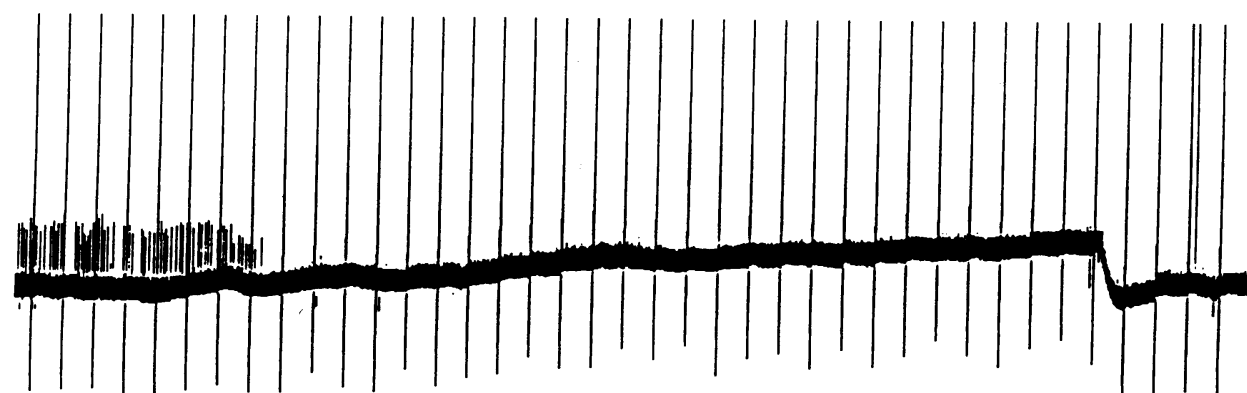

*

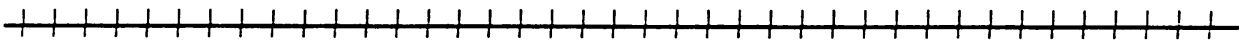

\section{Anoxia}

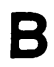

Figure 2. Inhibition of spontaneous excitatory postsynaptic potentials (EPSP) during anoxia. $(A) \mathrm{A}$ continuous recording of membrane potential (upper) before, during, and after anoxia with baseline membrane potential of $-81 \mathrm{mV}$. Action potentials and membrane input resistance were monitored with current pulses $(0.4 \mathrm{nA}$ and $-0.3 \mathrm{nA}$ [lower trace]). Small inflection present during baseline and the first 1.5 min of anoxia were spontaneous EPSPs that became totally suppressed during the rest of the anoxic period and the first $8 \mathrm{~min}$ after reoxygenation (not shown). Note that action potentials were clipped. (B) A snapshot of EPSPs from the upper trace in $A$ at the asterisk. Note the increased amplitude during membrane hyperpolarization. Calibration: $20 \mathrm{mV}$ and $2 \mathrm{~min}$ for $A ; 20 \mathrm{mV}$ and 800 $\mathrm{ms}$ for $B$. 


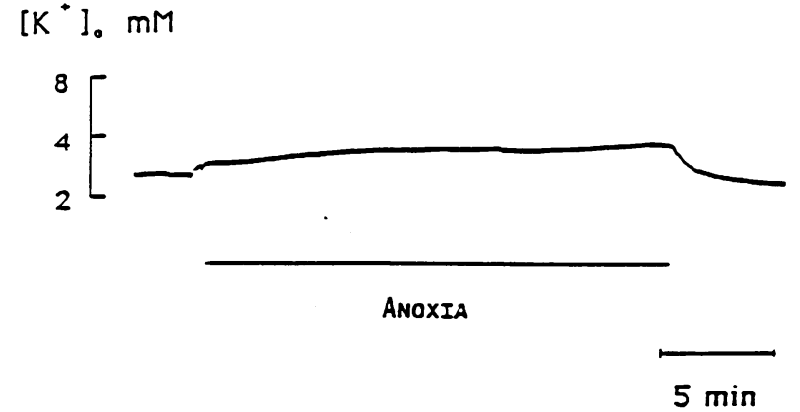

Figure 3. Change in extracellular $\mathrm{K}^{+}$concentration $\left(\mathrm{K}_{0}^{+}\right)$during anoxia. $\mathrm{K}_{0}^{+}$was measured using double-barreled microelectrodes. Anoxia $(20 \mathrm{~min})$ induced only a modest increase in $\mathrm{K}_{0}^{+}(1-2 \mathrm{mM})$.

was carried out as has been previously described $(7,15)$ with the following modifications: up to eight $300-\mu \mathrm{m}$ slices (taken from the same tissue used for the slice recordings) were maintained in Ringer's saline $\left(\right.$ at $32^{\circ} \mathrm{C}$ ). After at least $1 \mathrm{~h}$, individual slices, as needed, were transferred to a second chamber for enzymatic treatment. Each slice was incubated with oxygenated Hepes-buffered saline ([in $\mathrm{mM}] 140 \mathrm{NaCl}$, $2.5 \mathrm{KCl}, 1 \mathrm{CaCl}_{2}, 1 \mathrm{MgCl}_{2}, 25$ dextrose, and 10 Hepes; $\mathrm{pH} 7.35$ ) containing a low concentration of trypsin $(0.15 \%$, type XI; Sigma Chemical Co., St. Louis, MO) at $32^{\circ} \mathrm{C}$ for $1 \mathrm{~h}$, then washed in fresh Hepes for $15 \mathrm{~min}$. Under a dissecting microscope, layers 3 and 4 were dissected out and the cells were dissociated by gentle trituration. Cells were plated in 35-mm plastic petri dishes for recording. Typically, around 50 cells were obtained from a $9-\mathrm{mm}^{2}$ piece of tissue. Whole-cell patchclamp recordings were conducted at room temperature $\left(\sim 22^{\circ} \mathrm{C}\right)$ as has been previously reported ( 7 ). Isolated neurons exhibiting a pyramidal morphology and a soma size of $12-25 \mu \mathrm{m}$ were selected for recording. Cells were not considered for analysis if the initial seal resistance was $<5 \mathrm{G} \Omega$, they had high leakage currents (holding current $>0.4 \mathrm{nA}$ at $-80 \mathrm{mV}$ ), membrane blebs, significant space clamp problems, or an access resistance $>15 \mathrm{M} \Omega$. In an attempt to minimize cytosolic wash- out and still maintain a reasonable access resistance, 4-6 $\mathrm{M} \Omega$ pipettes were used. The average access resistance was $10.7 \pm 3 \mathrm{M} \Omega(n=56)$. Access resistance was monitored throughout the experiment and data were not used if resistance changes occurred.

For initial experiments the external solutions was Hepes-buffered saline and the pipette solution contained (in mM) $150 \mathrm{KF}, 5$ EGTA, 10 Hepes, and 9 glucose at $\mathrm{pH} 7.35$. In the current-clamp recording mode, these neurons had an average membrane potential of $-59 \pm 6$ $\mathrm{mV}(n=8$, mean $\pm \mathrm{SD})$, an input resistance of $488 \pm 243 \mathrm{M} \Omega$ and exhibited spontaneous and repetitive action potentials with a magnitude of 85-105 mV (which may be due to the loss of inhibitory inputs). In the voltage-clamp recording mode, cells displayed transient voltage-dependent inward currents and sustained voltage-dependent outward currents. For the majority of experiments (which focused on sodium currents), $0.5 \mathrm{mM} \mathrm{CdCl}_{2}$ was added to the external solution to block calcium currents and $\mathrm{Cs}^{+}$was substituted for $\mathrm{K}^{+}$in the pipette solution to block potassium currents. With tetrodotoxin $(1 \mu \mathrm{M})$ or saxitoxin $(0.5 \mu \mathrm{M})$ in the bath, no voltage-dependent currents were observed when recording with $\mathrm{Cs}^{+}$in the pipette and $\mathrm{Cd}^{++}$in the bath. Linear leak subtraction, based on resistance estimates from five hyperpolarizing pulses applied before the depolarizing test potential, was used for all voltage clamp recordings. Membrane currents were filtered at $5 \mathrm{KHz}$ and sampled at $20 \mathrm{KHz}$. Zero-oxygen (obtained with oxygen scavenger sodium hydrosulfite, $1 \mathrm{mM}$, added to Hepes solution equilibrated with $100 \% \mathrm{~N}_{2}$ ) and sodium cyanide $(\mathrm{CN})$ solutions $(2 \mathrm{mM})$ were applied using a Pico-Spritzer coupled to a micropipette ( $25-\mu \mathrm{m}$ tip) positioned $\sim 50 \mu \mathrm{m}$ from the recorded cell. The Pico-spritzer was adjusted before each experiment to obtain a constant flow rate of $2-4 \mu \mathrm{l} / \mathrm{min}$ from the micropipette. In one set of experiments, $1 \mathrm{mM} \mathrm{CN}$ was added to the extracellular solution 5-10 min before patching cells of interest. The osmolarity of all solutions was adjusted to 300 mosM.

\section{Results and Discussion}

Cellular properties of human neocortical neurons in the slice. 49 neurons, from layers 3 and 4, were studied in slice experiments. These neurons showed a Vm of $-77 \pm 6 \mathrm{mV}$
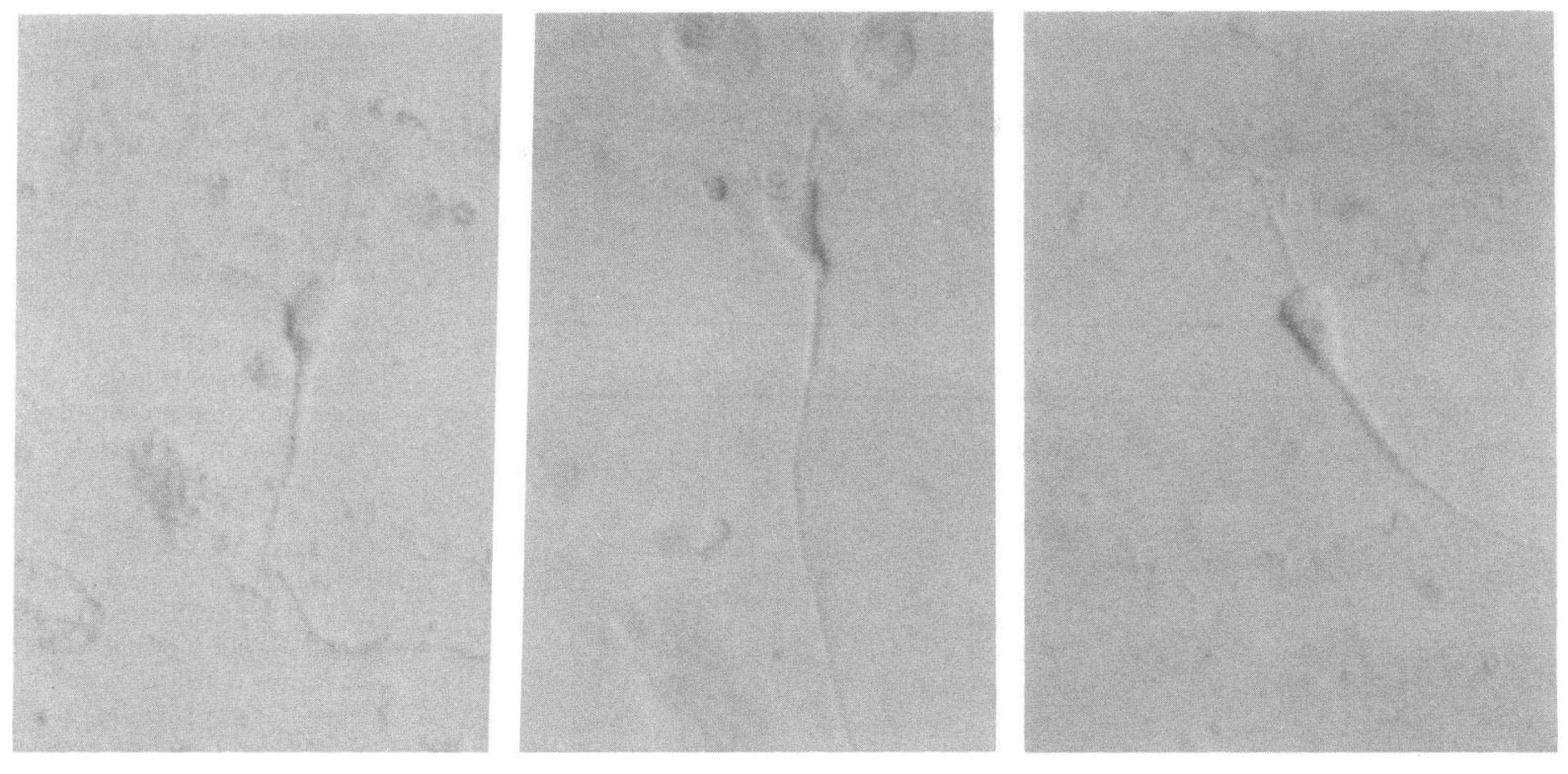

Figure 4. Photomicrographs of dissociated adult human neocortical neurons showing typical morphology of cells selected for recording. Only neurons exhibiting a pyramidal morphology and a soma size of $12-25 \mu \mathrm{m}$ were selected. Scale bar, $50 \mu \mathrm{m}$. 


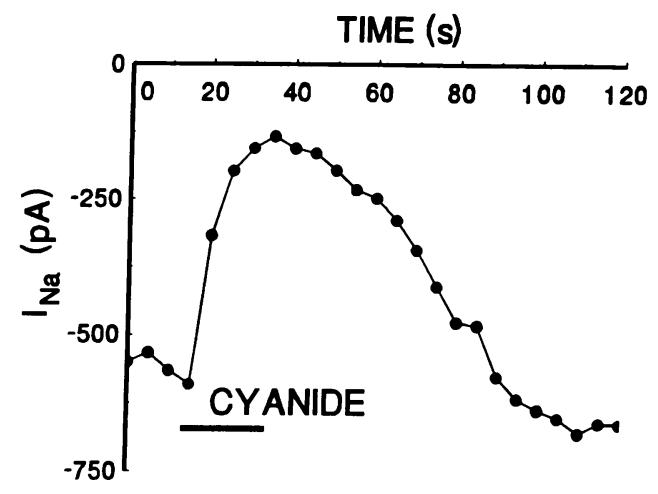

Figure 5. CN inhibits $I_{\mathrm{Na}}$ in adult human neocortical neurons. The effect of $\mathrm{CN}$ without ATP in the recording pipette. Recordings were obtained in the whole-cell voltage-clamp mode. Cells were held at $-70 \mathrm{mV}$ and stepped to $0 \mathrm{mV}$ for $10 \mathrm{~ms}$ every $5 \mathrm{~s}$. CN was applied for $20 \mathrm{~s}$ after the fourth trial.

(mean \pm SD) and an amplitude of action potentials of $91 \pm 6$ $\mathrm{mV}$. Rn of these cells was $57 \pm 25 \mathrm{M} \Omega$ (range 23-111 M $\Omega$ ). Other membrane properties such as postinhibitory rebound, delayed excitation, spike frequency adaptation, inward rectification, and after-hyperpolarization were also found in these cells, although to various degrees.

Effects of anoxia on human neocortical neurons in the slice. To examine the effect of anoxia on human neocortical neurons, slices were exposed to anoxia for $10-30 \mathrm{~min}$. We observed three main electrophysiologic changes relating to $\mathrm{Vm}$, $\mathrm{Rn}$, and neuronal excitability. Vm showed a biphasic response to anoxia in most neurons (30/36) (Fig. 1). The initial phase, occurring in the first few minutes (3-8 $\mathrm{min}$ ) of anoxic exposure, consisted of a relatively small hyperpolarization ( $5.5 \pm 7.4$ $\mathrm{mV})$. Vm then started to become more positive, returning to baseline and stabilizing for another 3-8 $\mathrm{min}$ at preanoxic levels. Neurons became depolarized after 8-15 min of anoxic exposure, although in six cells this second phase did not appear before $25 \mathrm{~min}$ into anoxia. The average depolarization was $8 \pm 8$ $\mathrm{mV}$ after an anoxic exposure lasting $18 \pm 7.0 \mathrm{~min}(n=30)$. A small number of neurons $(6 / 36)$ did not show any hyperpolarization and rapidly depolarized by $20-30 \mathrm{mV}$ in $\sim 6 \mathrm{~min}$. Although $\mathrm{Rn}$ did not change in the first several minutes of anoxia, it decreased in all cells and, by the end of the exposure period, the mean maximum decrease was $44 \pm 15 \%(n=36)$.

During these studies, we were intrigued to see that neuronal excitability was markedly decreased early during anoxic exposure (Fig. 1), sometimes even in the absence of $\mathrm{Vm}$ or $\mathrm{Rn}$ changes. Indeed, before there was any change in $\mathrm{Rn}$ and at a time when $\mathrm{Vm}$ was either still at or had returned to baseline levels (before depolarization), rheobase was found to increase by $1.7 \pm 0.4$ times $(P<0.001, n=19)$. The rheobase continued to increase throughout the anoxic exposure and reached a maximum of $2.6 \pm 0.7$ times $(P<0.001, n=10)$. Furthermore, there was a major inhibition of excitatory postsynaptic potentials (EPSPs): spontaneous EPSPs were completely suppressed within the first $5 \mathrm{~min}(2.5 \pm 1.0 \mathrm{~min}, n=17)$ of anoxia (Fig. 2).

Potassium ionic homeostasis during anoxia in the human neocortex. In the brainstem and hippocampus, previous studies have shown that the anoxia induced changes in $V m$ and $R n$ are correlated with a marked increase in extracellular $\mathrm{K}^{+}$activity
A

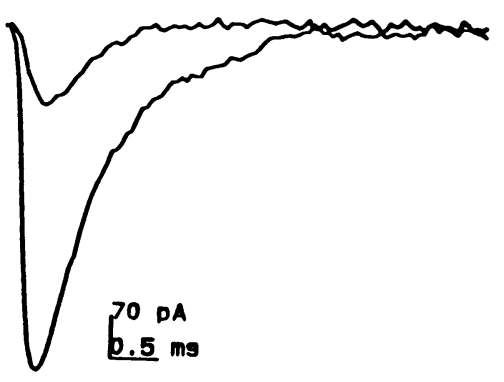

C

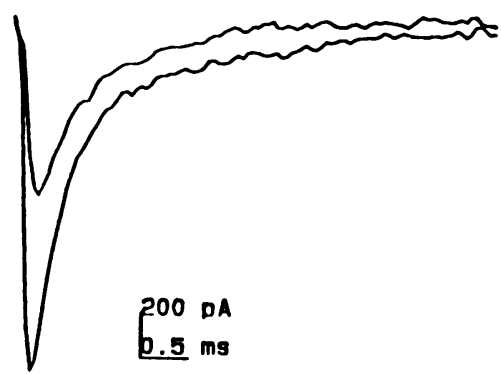

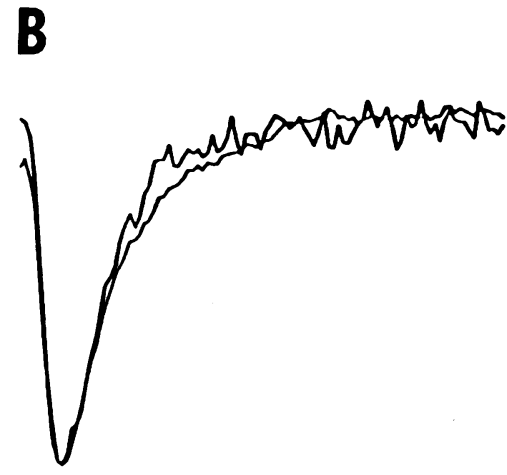

Figure 6. Representative traces showing the effect of $\mathrm{CN}(A$ and $B)$ and anoxia $(C$ and $D)$ on fast activation and inactivation kinetics. Cells were held at $-70 \mathrm{mV}$ and stepped to 0 $\mathrm{mV}$ for $10 \mathrm{~ms}$ every $5 \mathrm{~s}$. (A) Superimposed recordings of $I_{\mathrm{Na}}$ before and during $\mathrm{CN}$. CN inhibited $I_{\mathrm{Na}}$. (B) Same tracings shown in $A$ except that the $\mathrm{CN}$ trace is shown scaled to the amplitude of the control tracing. Note that the kinetics of activation and inactivation are the same before and after $20 \mathrm{~s} \mathrm{CN}$. ( $C$ ) Superimposed recordings of $I_{\mathrm{Na}}$ before and after $1 \mathrm{~min}$ of anoxia. Anoxia inhibited $I_{\mathrm{Na}}$. $(D)$ Same tracings shown in $C$ except that the anoxia trace is shown scaled to the amplitude of the control tracing. Again, note that the kinetics of activation and inactivation are the same before and during anoxia. 
$\left(\mathrm{K}_{0}^{+}\right)(9-11,16)$. Therefore, we measured $\mathrm{K}_{0}^{+}$using doublebarreled ion-selective microelectrodes. Experiments were carried out in five human neocortical brain slices. Baseline $\mathrm{K}_{0}^{+}$ was $\sim 2.8 \mathrm{mM}$ and it increased in the first few minutes by an average of $1.2 \mathrm{mM}$. This was followed by a slow and small increase in $\mathrm{K}_{0}^{+}$reaching a total of 4-5 $\mathrm{mM}$ after $20 \mathrm{~min}$ of anoxia (Fig. 3).

We were surprised to observe that human neocortical neurons maintained $\mathrm{Vm}$ and $\mathrm{Rn}$ for 15-20 min with a complete lack of $\mathrm{O}_{2}$. Parallel ongoing experiments in our laboratory on rat neocortical slices have shown, however, similar patterns of electrophysiologic changes (unpublished data). This contrasted with previous studies on rat hippocampal and brain- stem tissue demonstrating major depolarization within much shorter periods of time (6-7 $\mathrm{min})(3-6,8-10)$.

Whole-cell patch-clamp recordings of human neocortical neurons. The hyperpolarization, decrease in $\mathrm{Rn}$, and elevation of $\mathrm{K}_{0}^{+}$could be explained by an increase in potassium conductance, as has been shown in previous studies in rat hippocampal and brainstem neurons $(3-6,8,9,14,17)$. However, since the anoxic depression of neuronal excitability could not be adequately explained by an increased potassium conductance alone, especially that, in some neurons, excitability was reduced before any changes in $\mathrm{Vm}$ or $\mathrm{Rn}$, we asked whether anoxia altered voltage-dependent inward currents. We therefore studied freshly dissociated human neocortical neurons in

\section{A}

\section{Control}

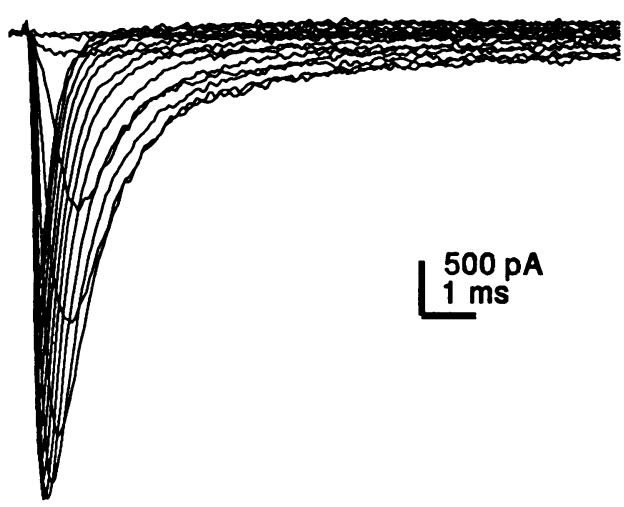

\section{Cyanide}

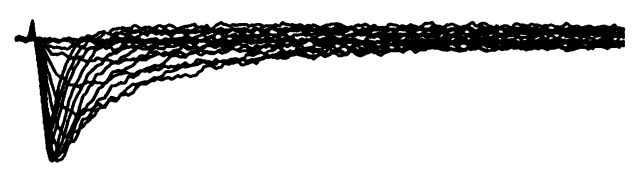

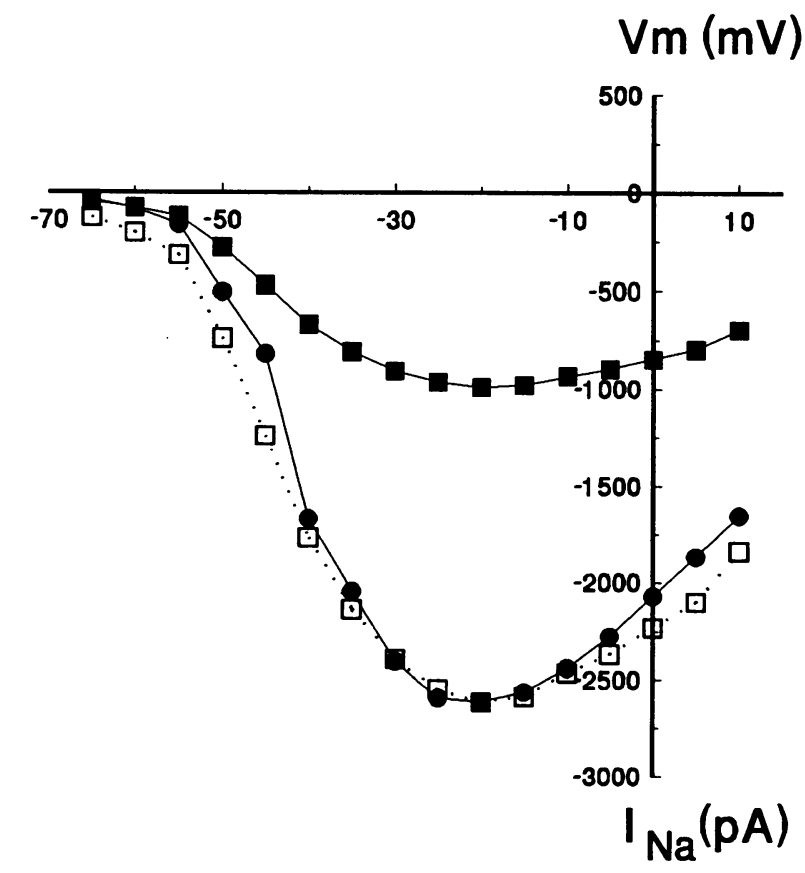

Figure 7. Effect of $\mathrm{CN}$ on the voltage dependence of sodium current activation. $(A)$ Tracings of membrane currents from a representative neuron before and after $\mathrm{CN}$ exposure. Currents were activated by depolarizing pulses ranging from -70 to $+10 \mathrm{mV}$ in $5-\mathrm{mV}$ increments. The holding potential was $-80 \mathrm{mV}$. (B) Voltage dependence of $\mathrm{I}_{\mathrm{Na}}$ before $(\bullet)$ and after ( $\bullet$ ) CN exposure. Data shown are averaged from six neurons and are obtained as described for $A$. Also shown is the CN I-V relationship scaled to control levels ( $\square$, dotted line), demonstrating that the voltage-dependence of activation is not altered. The data points were fit with a Boltzman equation. The mean potential for half-maximal activation, $\mathrm{V} 1 / 2$, was -37.5 before and -38.6 after $\mathrm{CN}$ exposure. The mean slope factor for activation, $K$, was 6.6 before and 8.1 after $\mathrm{CN}$ exposure. 
order to voltage-clamp membrane currents effectively (15). Using the whole-cell patch-clamp technique (14) 63 pyramidal neurons (Fig. 4) were studied. Inasmuch as inhibition of the sodium current could underlie the decreased excitability seen in the slice preparation, and because of our previous results with rat hippocampal CA1 neurons (7), the following wholecell studies focused on the voltage-dependent sodium current.

Using cesium fluoride in the pipette solution and $\mathrm{CdCl}_{2}$ in the bath, neurons displayed only a fast-activating, fast-inactivating inward current $\left(I_{\mathrm{Na}}\right)$ that was blocked by tetrodotoxin ( 1 $\mu \mathrm{M})$. This current activated at around $-50 \mathrm{mV}$ and had a peak current at $-30 \mathrm{mV}$. Cells were studied before and after perfusion with metabolic inhibitors $(2 \mathrm{mM} \mathrm{NaCN})$ or zero-oxygen solution (anoxia, measured $\mathrm{Po}_{2}=0$ torr). $\mathrm{CN}$ markedly decreased the magnitude of $I_{\mathrm{Na}}$ (elicited by stepping to $0 \mathrm{mV}$ from a holding potential of $-70 \mathrm{mV}$ ) by $48 \pm 17 \%$ in a short period ( $n$ $=12$ ). This inhibition was reversible, with partial recovery occurring within $5 \mathrm{~min}$ (Fig. 5). Anoxia decreased $I_{\mathrm{Na}}$ in human neocortical neurons by $33 \pm 8 \%(n=5)$, but typically the response took two to three times longer to elicit than with $\mathrm{CN}$. Neither CN nor zero-oxygen solutions had significant effects on the time to peak or the kinetics of fast inactivation (Fig. 6). The time constant for inactivation was $0.46 \mathrm{~ms}$ before and 0.47 ms after cyanide application $(n=15)$.

$\mathrm{CN}$ decreased the magnitude of $I_{\mathrm{Na}}$ at all command potentials, but had little effect on the threshold for current activation and the occurrence of the peak current (Fig. $7 \mathrm{~A}$ ). In fact, $\mathrm{CN}$ shifted the $I-V$ curve by only $4 \pm 4 \mathrm{mV}$ in the positive direction $(n=7)$. Similarly, zero-oxygen exposure did not significantly alter the $I-V$ relationship.

The effect of metabolic inhibition on steady-state inactivation was also examined. Both $\mathrm{CN}$ and zero-oxygen had a major effect on the voltage dependence of steady-state inactivation.
The midpoint of the steady-state inactivation curve [ $h \infty(V)]$ was shifted in the negative direction by $21 \pm 6 \mathrm{mV}(n=12)$ and $17 \pm 6 \mathrm{mV}(n=6)$ with $\mathrm{CN}$ and zero-oxygen solutions, respectively. The spontaneous shift in the $h \infty(V)$ curve for a corresponding time period ( $1 \mathrm{~min}$ ) was $<1 \mathrm{mV}(0.9 \pm 0.6 \mathrm{mV} / \mathrm{min}$, $n=7$ ).

To check that voltage clamp errors were not biasing the results, experiments were done using a reduced sodium gradient (20 mM Na${ }_{0}^{+}, 5 \mathrm{mM} \mathrm{Na}_{i}^{+}$), large pipette tips (2-4 M $\Omega$ ) and $80-90 \%$ series resistance compensation. The estimated maximum error for clamp potential was $4 \pm 2 \mathrm{mV}$. CN decreased the magnitude of $I_{\mathrm{Na}}(38 \pm 15 \%, n=5)$ when the cells were held at $-70 \mathrm{mV}$ and stepped to $0 \mathrm{mV}$. The midpoint of the $h \infty(V)$ curve, as determined with a Boltzman function, shifted $-24 \mathrm{mV}$ in the hyperpolarizing direction (Fig. $8 \mathrm{~A}$ ). The slope of the $h \infty(V)$ curve decreased dramatically, with the slope factor, $K(\mathrm{mV}$ per $e$-fold change in peak current $)$ changing from 6.5 to 13.4 . To verify that the shift was not affected by the perfusion system, we did two additional sets of experiments. Perfusing cells with saline had almost no effect on the magnitude of $I_{\mathrm{Na}}(0.4 \pm 5.3 \%$ increase, $n=5)$ or the $h \infty(V)$ curve. In the second set, cells were exposed to $1 \mathrm{mM} \mathrm{CN}$ for 5-10 minutes before being patched. When the $h \infty(V)$ curve for these cells was compared with the baseline values for the cells above, a shift of $15 \mathrm{mV}$ in the negative direction was seen (Fig. $8 B, n=4$ ). The $K$ for these cells was $8.8 \mathrm{mV}$ per $e$-fold.

To determine whether ATP plays an important role in maintaining $I_{\mathrm{Na}}$, whole-cell recordings were made with electrodes containing 2-10 $\mathrm{mM} \mathrm{K}_{2} \mathrm{ATP}(n=16)$. When holding these cells at $-70 \mathrm{mV}$ and stepping to $0 \mathrm{mV}, \mathrm{CN}$ decreased the magnitude of $I_{\mathrm{Na}}$ by only $8 \pm 9 \%(n=15)$ (Fig. $\left.9 A\right)$. Further, the negative shift in the $h \infty(V)$ curve was $7 \pm 4 \mathrm{mV}(n=10)$ (Fig. $9 B$ ), indicating that intracellular ATP levels are crucial

A

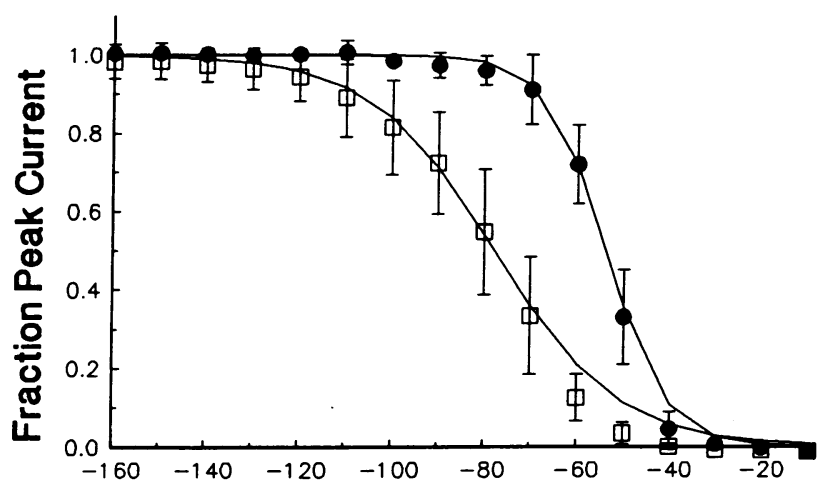

Test Potential (mV)

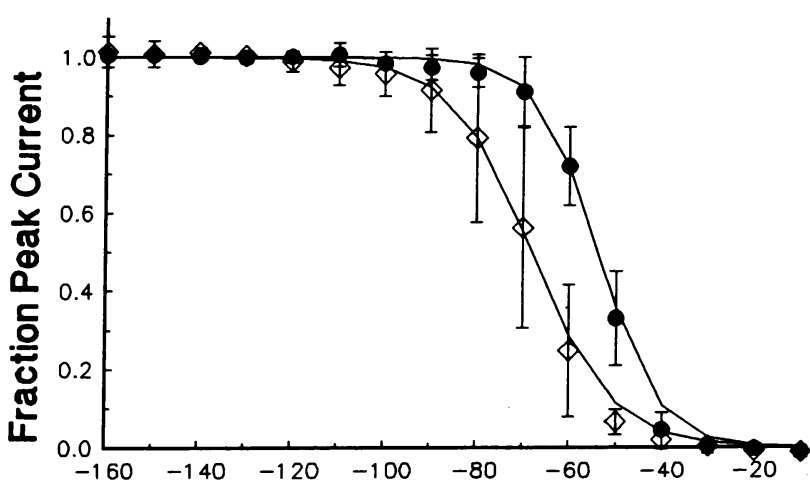

Test Potential (mV)

Figure 8. Normalized steady-state inactivation curve of $I_{\mathrm{Na}}$ before and during $\mathrm{CN}$ exposure. The pre-potential, varied from $-130 \mathrm{mV}$ to $-45 \mathrm{mV}$ in $5-\mathrm{mV}$ increments, was held constant for $500 \mathrm{~ms}$ prior to a command potential to $-10 \mathrm{mV}$. $(A)$ Data points (averages from seven neurons) were obtained before $(\bullet)$ and during $(\square) \mathrm{CN}$ exposure and are all normalized to the maximum current obtained during the control trial. The smooth curves are obtained from a Boltzman equation with $V^{1 / 2}=-53.9$ and $K=6.5$ before and $V^{1 / 2}=-77.8$ and $K=13.4$ during CN exposure. This $\mathrm{CN}$ induced shift reduces the fraction of channels available for activation at $-60 \mathrm{mV}$ from 0.75 to around 0.20 . (B) Comparison of neurons $(n=4)$ exposed to $\mathrm{CN}$ for 5-10 min before patching $(\diamond)$ with control data $(\bullet)$ from $A$. The Boltzman parameters are $V 1 / 2=-68.1$ and $K=8.8$ for the cells exposed to $\mathrm{CN}$. The fraction of channels available for activation at $-60 \mathrm{mV}$ is reduced to around 0.25 in cells exposed to $\mathrm{CN}$ as compared with 0.75 for the control group. 
A

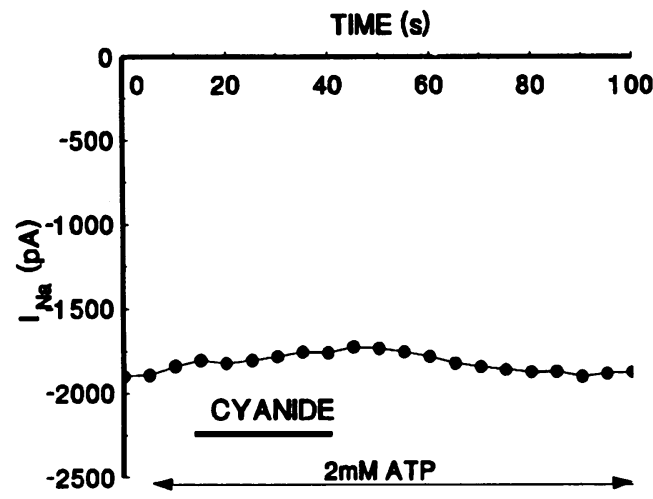

B

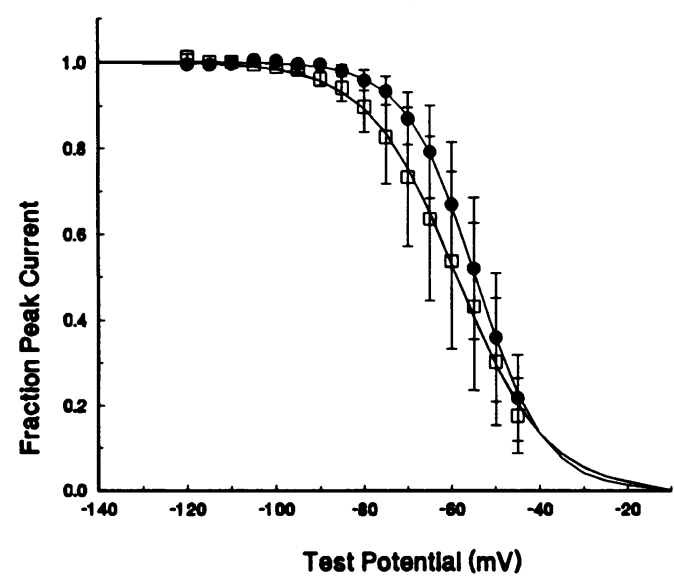

Figure 9. The effect of $\mathrm{CN}$ with ATP $(2 \mathrm{mM})$ in the recording pipette. Inclusion of ATP in the recording pipette greatly reduced the $\mathrm{CN}$ induced inhibition of $I_{\mathrm{Na}}$. $(A)$ Recordings were obtained in the whole-cell voltage-clamp mode. Cells were held at $-70 \mathrm{mV}$ and stepped to $0 \mathrm{mV}$ for $10 \mathrm{~ms}$ every $5 \mathrm{~s}$. CN was applied for $20 \mathrm{~s}$ after the fourth trial. ( $B$ ) Normalized steady-state inactivation curve of $I_{\mathrm{Na}}$ before ( $\bullet$ ) and during $(\square) \mathrm{CN}$ exposure. The prepotential, varied from $-120 \mathrm{mV}$ to $-45 \mathrm{mV}$ in $5-\mathrm{mV}$ increments, was held constant for $500 \mathrm{~ms}$ before a command potential to $-10 \mathrm{mV}$. Data points shown are averaged from four neurons. The smooth curves are obtained from a Boltzman function with $V^{1 / 2}=-54.6$ and $K=7.8$ before and $V^{1 / 2}=-58.8$ and $K=10.0$ during $\mathrm{CN}$ exposure. The fraction of channels available for activation at $-60 \mathrm{mV}$ is around 0.65 before and 0.55 during $\mathrm{CN}$ exposure.

in the modulation of $I_{\mathrm{Na}}$ when human neocortical neurons are deprived of $\mathrm{O}_{2}$.

This is the first study of membrane currents in adult human cortical neurons, demonstrating that dissociation of neurons from adult human brains can be successfully performed and isolated neurons studied. Our voltage-clamp recordings of neocortical neurons also provide the first direct evidence for the notion that anoxic depression of human neocortical activity is largely mediated by modulations of $I_{\mathrm{Na}}$.

The mechanism underlying the negative shift of the steadystate inactivation curve is not completely clear. This rapid nega- tive shift elicited by anoxia or $\mathrm{CN}$ may constitute the same mechanism that underlies the gradual run-down of sodium currents that occurs with whole-cell recordings. Showing that the inclusion of ATP in the pipette greatly reduces the anoxicinduced shift in the $h \infty(V)$ curve supports our hypothesis that this shift is due to a reduction in oxidative metabolism. Our data also suggest that ATP can either directly modulate the channel as a ligand or play a role in $\mathrm{Na}$ channel modulation by phosphorylation, as has been shown recently with rat brain sodium channels $(18,19)$.

We conclude therefore that oxygen deprivation increases the probability for sodium channels to be in the inactive state. We postulate that the rapid suppression of neocortical excitability by anoxia via sodium channel modulation is an adaptive measure aimed at reducing the mismatch between cellular metabolic demand and $\mathrm{O}_{2}$ supply, thus possibly leading to an enhancement of neuronal survival. Depolarization of neurons, often observed during anoxia (3-9, our current data) is associated with an influx of calcium, an event which enhances neuronal injury and death $(20,21)$. Hence, it is no surprise that therapeutic research efforts have focused so far on $\mathrm{Ca}^{++}$regulation (20-22). An alternative strategy, however, would involve exploiting this intrinsic energy saving mechanism that we describe in this work in an attempt to delay the onset of the second phase (e.g., depolarization) of the neocortical response to anoxia (23-25). In concept, this adaptive mechanism is similar to that described recently by us and other investigators (26, 27 ) involving ATP-sensitive $\mathrm{K}^{+}$channels and linking metabolic activity of the nerve cell to its membrane biophysical properties and excitability. It is the understanding of these mechanisms and their regulatory pathways that will lead us in the future to a better appreciation of cellular adaptation to stress, survival strategies and cell injury.

\section{Acknowledgments}

We thank Dr. D. D. Spencer for his invaluable help in obtaining the tissue and reviewing the manuscript and R. Garcia for his technical assistance.

This work was supported by National Institutes of Health research grants HL-39924, HD-15736, and HD-28940 to Dr. Haddad, a predoctoral fellowship from National Institutes of Health Eye Institute training grant EYO-7115-02 to T. Cummins, and a fellowship from the Parker Francis Family Foundation to Dr. Jiang.

\section{References}

1. Rossen, R., H. Kabat, and J. P. Anderson. 1943. Acute arrest of cerebral circulation in man. Arch. Neurol. Psychiatry. 50:510-528.

2. Siesjo, B. K. 1988. Calcium, ischemia, and death of brain cells. In: Part III Neurological Disease. Ann. N. Y. Acad. Sci. 522:638-661.

3. Fujiwara, N., H. Higashi, K. Shimoji, and M. Yoshimura. 1987. Effects of hypoxia on rat hippocampal neurons in vitro. J. Physiol. (Lond.). 384:131-151.

4. Krnjević, K., and J. Leblond. 1989. Changes in membrane currents of hippocampal neurons evoked by brief anoxia. J. Neurophysiol. 62:15-30.

5. Leblond, J., and K. Krnjević. 1989. Hypoxic changes in hippocampal neurons. J. Neurophysiol. 62:1-14.

6. Shimoji, K., H. Higashi, N. Fujiwara, S. Fukuda, and M. Yoshimura. 1989. Hypoxia in brain slices. Biomed. Biochim. Acta. 48:S149-154.

7. Cummins, T. R., D. F. Donnelly, and G. G. Haddad. 1991. Effect of metabolic inhibition on the excitability of isolated hippocampal CA1 neurons: developmental aspects. $J$. Neurophysiol. 66:1471-1482.

8. Haddad, G. G., and D. F. Donnelly. $1990 . \mathrm{O}_{2}$ deprivation induces a major depolarization in brainstem neurons in the adult but not in the neonatal rat. $J$. Physiol. (Lond.). 429:411-428.

9. Jiang, C., and G. G. Haddad. 1991. Effect of anoxia on intracellular and 
extracellular potassium activity in hypoglossal neurons in vitro. J. Neurophysiol. 66:103-111.

10. Donnelly, D. F., C. Jiang, and G. G. Haddad. 1992. Comparative responses of brainstem and hippocampal neurons to $\mathrm{O}_{2}$ tension: in vitro intracellular studies. Am. J. Physiol. 262:L549-L554.

11. Kawasaki, K., S. F. Traynelis, and R. Dingledine. 1990. Different responses of CA1 and CA 3 regions to hypoxia in rat hippocampal slice. J. Neurophysiol. 63:385-394.

12. McCormick, D. A. and A. Williamson. 1989. Convergence and divergence of neurotransmitter action in human cerebral cortex. Proc. Natl. Acad. Sci. USA. 86:8098-8102.

13. Jiang, C., S. Agulian, and G. G. Haddad. 1991. $\mathrm{O}_{2}$ tension in adult and neonatal brain slices under several experimental conditions. Brain Res. 568:159164.

14. Hamill, O. P., A. Marty, E. Neher, B. Sakmann, and F. J. Sigworth. 1981. Improved patch-clamp technique for high-resolution current recording from cells and cell-free membrane patches. Pflugers Arch. Eur. J. Physiol. 391:85-100.

15. Kay, A. R. and R. K. S. Wong. 1986. Isolation of neurons suitable for patch-clamping from adult mammalian central nervous systems. J. Neurosci. Methods. 16:227-238.

16. Hansen, A. J., J. Hounsgaard, and H. Jahnsen. 1982. Anoxia increases potassium conductance in hippocampal nerve cells. Acta Physiol. Scand. 115:301-310.

17. Hansen, A. J. 1985. Effect of anoxia on ion distribution in the brain. Physiol. Rev. 65:101-148.
18. Sigel, E. and B. Baur. 1988. Activation of protein kinase $C$ differentially modulates neuronal $\mathrm{Na}^{+}, \mathrm{Ca}^{2+}$, and $\gamma$-aminobutyrate type A channels. Proc. Natl. Acad. Sci. USA. 85:6192-6196.

19. Numann, R., W. A. Catterall, and T. Scheuer. 1991. Functional modulation of brain sodium channels by protein kinase C phosphorylation. Science (Wash. DC). 254:115-118.

20. Rothman, S. M. 1983. Synaptic activity mediates death of hypoxic neurons. Science (Wash. DC). 220:536-537.

21. Meyer, F. B. 1989. Calcium, neuronal hyperexcitability and ischemic injury. Brain Res. Rev. 14:227-243.

22. Choi, D. W. 1990. Cerebral hypoxia: some new approaches and unanswered questions. J. Neurosci. 10:2493-2501.

23. Hochachka, P. W. 1986. Defense strategies against hypoxia and hypothermia. Science (Wash. DC). 231:234-241.

24. Boening, J. A., I. S. Kass, J. E. Cottrell, and G. Chambers. 1989. The effect of blocking sodium influx on anoxic damage in the rat hippocampal slice. Neuroscience. 33:263-268.

25. Edwards, R. A., P. L. Lutz, and D. G. Baden. 1989. Relationship between energy expenditure and ion channel density in the turtle and rat brain. Am.J. Physiol. 256:R1354-R1358.

26. Ben-Ari, Y. 1989. Effect of glibenclamide, a selective blocker of an ATP$\mathrm{K}^{+}$channel, on the anoxic response of hippocampal neurons. Pflügers Arch. Eur. J. Physiol. 414:S111-114.

27. Jiang, C., Y. Xia, and G. G. Haddad. 1992. Role of ATP-sensitive $\mathrm{K}^{+}$ channels during anoxia: Major differences between rat (newborn, adult), and turtle neurons. J. Physiol. (Lond.). 448:215-225. 